\title{
Analyses of the Cultural Differences in Chinese and American Cartoon Movies

\author{
Zhou Tianjuan ${ }^{1, a}$
} \\ ${ }^{1}$ International School, Canvard College, Beijing Technology and Business University, Tongzhou District, Beijing, China. \\ aztj1980.student@sina.com.
}

Keywords: culture differences; cartoon movies; China and America

\begin{abstract}
Cultural differences are reflected in various places, such as in cartoon movies. Study on cultural differences may help to learn from the other cultures and to promote and spread the national cultures and values. In the paper, the author mainly analyzes differences between American and Chinese cartoon movies in terms of theme, creation of characters, action design and values, as well as the culture features reflected in those four sides. At last, the paper suggests that Chinese should take advantages of useful parts of American cultures reflected in cartoon movies, to promote the development of Chinese cartoon movies industry.
\end{abstract}

\section{Introduction}

In the modern society, cultural differences may be reflected in various ways. As a mainstay industry, cartoon movies can broadcast culture, values and attitudes of a unique nation in a comically and breezily way. The American culture is spread widely through animation industry. In the recent years, Chinese cartoon industry has got very good development. More and more Chinese cultures are conveyed to the audiences at home and abroad. A careful study will reveal the cultural differences in Chinese and American cartoon movies, that is, the difference in theme, character, action design and values.

\section{Cultural Differences in Chinese and American Cartoon Movies}

\subsection{The Differences in the Themes of Cartoon Movies}

Themes in American cartoon movies are diversified with the following kinds.

Firstly, endearment of freedom can be easily found in American cartoon movies, such as Chicken Run and Spirit Stallion of the Cimarron. In order to avoid being killed,crowds of chicken succeed in running away and save themselves in the story named Chicken Run. Spirit Stallion of the Cimarron is a vivid example to express American freedom, in which with the help of Indians, the little horse comes back to his world, regaining his nature. In all, these movies advocating freedom are representative of American culture.

Secondly, American always make individual life first place, and Ant's Adventure is the typical example. Briefly speaking, a worker ant named $\mathrm{Z}$ manages to change his fate and becomes the hero of the ants' kingdom. In addition, Egyptian prince also shows the same theme obviously.

Thirdly, family love, friendship and affection are also the common themes American cartoon movies, such as The Lion King, and Finding Nemo. Although the cartoon movie Beauty and the Beast seems to be a beautiful story about love, it tells people a story that a beautiful girl saves her father, similar to the story of the Chinese cartoon movie Lotus Lantern.

Fourthly, the theme of environment and nature conservation are fully reflected in the movies. Ice Age is the most typical work which describes in the wild times human and animals are at odds. However, three kinds of animals with different characters get together, not only take care of a 
human's baby, but overcome tremendous troubles to get the baby back home, showing that human beings and nature ought to be together in harmony, co-existence and co-prosperity.

To be contrast, the theme of Chinese animation is relatively simple, regardless of the early works Proud of the General, Little Tadpole Looking for Mom or recent cartoon movies Avanti's Story, Lotus Lantern. All these works tend to be instructive and didactic. Animated characters in Chinese cartoon movies, no matter whether naive figures or legendary heroes, invariably bear the profound impact of traditional Confucian culture. Compared to American cartoon movies, Chinese animation emphasizes too much on its educational function, always with a strong preaching purpose, so that Chinese cartoons with rigid theme fail to attract adults. Because traditional thoughts can be easily found in the Chinese animation, and many of the classic animated images are not specifically created for the animation, therefore there are few unforgettable characters like Mickey Mouse, Donald Duck, and Garfield have been created in Chinese cartoon movies.

\subsection{The Differences in the Creation of Characters}

Beginning with Disney animation, American cartoon movies prefer to tell the stories of human beings through animals images. Actually these transformed images are more kinds of symbols of human beings than these cute animals themselves which are fulfilled with human beings' consciousness, under covering with animals' appearances. In a word, to be simple or exaggerated in personalities naturally belongs to American animation.

Simply speaking, the images of American animation characters are usually exaggerated. Most of them are images with big head, big eyes and big hands, but are very lovely with features of animals' essential characteristics, such as Shrek. A number of facts all along prove that Americans are good at modeling typical characters and producing animation stars. The United States have made thousands upon thousands kinds of animation models and produced kinds of typically lively cartoon movie stars which are widely popular and enjoyed by people all around the world.

The leading roles in the American cartoon movies fully display the American culture of individual heroism. In the view of movie-makers, a hero safeguarding all of humanity belongs to the United States, as well as to the whole world. Mulan is a typical example of this idea. In Chinese culture Mulan is full of loyalty and filial piety, but in American cartoon movies she is a girl with heroism, performed perfectly in western stage. The cartoon movie Mulan not only earned 300 million dollars for the Unite States, but made heroism epidemic globally, and gradually became fashionable.

The characters in Chinese cartoon movies are attached to eastern classical images, full of national features. Compared to American cartoons, Chinese ones prefer to emphasize on characters' spirits, rather than images. Chinese do well in grabbing details and outlining characters. For instance, in the famous Chinese animation Monkey King, the typical character Hesperus Taibai has the unique image with a fat face, two groups of white triangle beard, a cone-shaped body and a pair of triangularly brown eyes covered with triangular eyebrows, which seems moderately elderly man outside but actually flattering, cunning quality inside.

Another characteristic of Chinese cartoon characters is that characters usually have obvious physical features of the ethnic, such as black eyes, black hair and yellow skin, full of ambition, absolute perfect human beings with all kinds of respected qualities. People always have an impression that a positive image of national animation is lifelike enough, highly personalized, equipped with noble sentiment, follows traditional ethics and morals, has pursuit of perfect ideal, endures the hardships, ignores the power and has superior ability. In a word, the characters are embodiment of ideals. There are no shortcomings in positive animation characters. However, it is just an ideal, a wish for integrity education. For example, as a Chinese hero in fairy tales, Monkey King is famous for its high skills, strong strength, wisdom and optimism. Another distinct character is Nezha, naive, brave and full of righteousness. 


\subsection{The Differences in the Action Designs}

The American cartoon movie makers attach much importance to the fluent and elastic action design in animation. In Snow White, the use of animation is taken to display the realistic model and action of characters just like human beings, to create realistic animation style, trying to combine this kind of realistic style with original cartoon style. So the lovely lady called Snow White is strictly drawn according to the structure of the human body without distortion and exaggeration, showing the handling of highly realistic style. Replacing animals, human beings become leading roles, thus establishing a realistic animation style and a completely different standard. And actions of the protagonist no longer retain the classic curves of variable flexibility, and even inertia and subsidiary movements are much less than before. Exaggerated movements and deformation of attraction are only used in animals as foils. Here clearly exists the idea of pragmatism in the American culture. In Americans' opinion, making sense is the truth. Pragmatism has greatly influenced American thoughts and actions, which brings up the temperament of the United States, and affects the entire world. Another characteristic feature reflected in American animation industry is that as long as they can make money, no matter what subversive roles cartoon movies need to create, Americans are ready to try and enjoy it.

There is a more stylized action design in the Chinese animation. For example, figures in Monkey King have stylized movements showing certain characteristics of Beijing Opera. The Monkey King flipping 108,000 thousands away, fighting with dozens of heaven soldiers and with the Skeleton Demon, all these scenes give people an impression that stylized thespian movements have a profound effect on the action design in Chinese animation, which becomes a remarkable Chinese style. Imago of the action design is another animated feature, which means, action is used to become a symbol to show spirits and emotions of characters, and which is unique feature of Chinese animation. The famous Chinese cartoon movie Three Monks can be referred to explain the definition of imago. In Three Monks, it impresses audiences that the music perfectly coordinates with movements to present characters' personalities. For example, the young monk's jumping action make him naive and smart, the chief monk's walking with swinging leg makes him rigid, cold and prim, and the fat monk's gently moving, carefully taking his shoes and grabbing his clothes function as kidding for his fat body to achieve entertainment effect on the one hand, and showing the kindness of monks on the other hand. This kind of action design reflects the Chinese people's emphasis on strictness and connotation. Actually Chinese people do not lack imagination. Unfortunately, they have no enough power to turn imagination into reality, so that little progress is made in Chinese animation industry.

\subsection{The Differences in the Values}

Having a higher popularity among audiences in the world, American cartoons, not only bring people spiritual pleasure, but also show the world unique American values which are free will, free choice, responsibility and humanity. Lion King, for its beautiful music, moving story and smooth images, and great epic animation has swept the world and people are still unable to forget it. Furthermore, American public pay most of their attention to achievements, and show admiration for heroes. That is to say, what becomes fashion is that Americans have great honor for achievements and heroes. Individual achievement is one of the highest values in the American evaluation system, which leads to the fact that Americans are always trying their best to be the number one. Love and responsibility are also the consistent topics in American cartoon movies. Perfect love and romanticism can be easily found in almost every cartoon movie. In the film, whether human beings or animals, bravely make their efforts to pursue love, in spite of great dedication. And there is also emphasis on family responsibilities, as well as selflessness among family in American cartoons. In Lion King, Simba and his friends finally defeat the scar, indicating the power of friendship. The entire film is full of the values of the United States and, tells the belief that by hard working, people can realize their "American dream". 
Humor, freedom are also important features of American culture, which are lively decided by naïve, lovely, active and non- authoritative American characteristics. For example, Tom and Jerry wonderfully shows the sense of humor in American culture. A mouse is a nausea animal across the street in the minds of most people, hated by everybody. However in the film it almost becomes the object of compassion, with no unpleasant sensation and just endless sense of humor. The cute mouse named Jerry often deals with brutality of a cat named Tom. However, their exaggerated performance entertains all spectators and makes them laugh. For example, Jerry' foot was carried tightly by naughty Tom, then Jerry fell down to floor, and Tom was complacent with exaggerated expression. And Tom sawed off a piece of stage when Jerry was performing in the stage, but it turned out to be that the stage around Jerry fell down while Jerry was still in safety, then Jerry was very happy just like a winner. In this way, people are deeply impressed by American type of exaggerated humor. And it can also be found in cartoon movie Cars, which best shows American sense of humor. It is a wonderful cartoon movie which has sense of humor in the details of performance, very unique and interesting. Therefore, cartoons of the Unite States successfully attract spectators all around the world. What's more, American cartoon movies are, not only popular with children, but also with adults, with fans of different ages. In all, the Unite States animation causes the whole spectators to resonate, and become an indispensable part of American common culture, creating a rare miracle in the history.

Obviously different from the American, Chinese people are steeped in Confucian education, and the benevolence, love, ritual, and justice have become the core of Chinese culture, which is well reflected in the classic Chinese ink painting cartoon movie Feelings of Mountains and Waters. The Chinese culture and the American one seem to have something in common, such as, the cultural thoughts which do favor to social unity for the management of national service. However, there are still obvious differences. For example, the Chinese culture stresses being mature and steady-going, while the American culture values free spirit; the Chinese culture prefers to love each other, while the American one prefers to love themselves; the Chinese culture agrees with collectivism, while the American one agrees with individualism; the Chinese culture tends to be graceful and restrained, while the American culture tends to be straightforward.

\section{Conclusion}

This paper has provided essential information and practical examples about important aspects of culture differences reflected in Chinese and American cartoon movies. Differences in cultural values affect the way in which planning is executed, decisions are made, strategy is implemented, and personnel are evaluated. And cultural differences are reflected in various places, not just in cartoons, but also in interpersonal relationships in daily life. The paper mainly analyzes differences between American and Chinese cartoon movies in terms of theme, creation of characters, action design and values, as well as the culture features reflected in those four sides.

As one of the largest power, the Unite States export their own cultural values, ideas and concepts to the world in the way of media, movies and books, etc. Most the values reflected in American cartoon movies are the precious treasure of human beings. Understanding cultural differences reflected in cartoon movies may help people know more about the gap between American and Chinese culture, improve the way of displaying national culture, and ultimately bring benefits to both countries. Therefore, Chinese should take advantages of useful parts of American cultures reflected in cartoon movies, to promote the development of Chinese cartoon movies industry.

\section{References}

[1] E.Addison: Saving the Women from Other Men: Disney's Aladdin. Camera Obscura(1993,31).

[2] W. B. Gudykunst, \& Y. Y. Kim, Communicating with Strangers: An Approach to Intercultural Communication. New York: McGraw Hill, Inc.( 1992). 
[3] F. Trompenaars: Riding the Waves of Culture: Understanding Cultural Diversity in Business. The Economist Books(1993,25), p. 7-9.

[4] Wang Li, Li Yujin: Chinese -American Cultural Differences in Cartoon Movies, Journal of Changchun Normal University(Humanities and Social Sciences)(2008,1), p94-95. 